\title{
X. OVERCOMING ADVERSITY IN ADOLESCENCE: NARRATIVES OF RESILIENCE
}

\author{
STUART T. HAUSER
}

\begin{abstract}
"Nothing is so fascinating or complicated as a trajectory of a human life. We emerge partly programmed at birth, and we change with our experiences thereafter. Some of us finally blow apart in adulthood like long-fuse time bombs0, while others grow to shine brightly like comets. Most of us have less spectacular careers, which are still hard to explain in hindsight, even to ourselves, and impossible to foresee in detail."

Jared Diamond (1995, p.16)
\end{abstract}

Jared Diamond (1995) offers this reflection in his review of E.O. Wilson's autobiography (Wilson 1994), a narrative highlighting the daunting challenges involved in understanding the course of individual lives. A distinguished biologist, Wilson describes his early origins as ones filled with major risks: the only child of parents divorced when he was seven, leaving him in the care of others; his father's debilitating alcoholism and eventual suicide; impaired hearing as a child; and in the year of his parent's divorce becoming virtually blind in one eye. Wilson's striking turn from early misfortune to stunning competence and success is a compelling feature of human life drawing the attention, curiosity, and extended energies of many of us to longitudinal studies. In our research program, we are using longitudinal narratives and new narrative analyses to discover basic mechanisms and pathways underlying the kind of surprising life course changes that Wilson chronicles, exemplifying resilient development.

Resilience refers to unexpected adaptation in the face of serious adversity. How such development occurs remains an unsolved mystery (Table 1).

Table 1. A Central Question Unterlying Studies of Resilience

What is it about some children and adolescents, their families, or their larger environments that allows them to maintain or subsequently achieve a positive developmental trajectory when many of their peers in similar circumstances are not able to do so?

(Adapted from Roosa 2000) 
Resilience has picked up many meanings in our popular culture competence, resilience perfume, resilient marijuana plants, resilient politicians, and the supposed-invulnerable child. Masten and colleagues (1990) point out that resilience can refer to three major classes of phenomena in the psychological literature. Different research approaches are associated with investigations of each set of phenomena:

1) Individuals in high-risk groups who have better-than-expected outcomes ("those who overcome the odds" against good development). Theoretical accounts and vignettes about successful people from highly disadvantaged backgrounds are of much interest to many psychiatric and social science observers (e.g., Beardslee \& Podorefsky 1988; Harrington \& Boardman 1997; Wang \& Gordon 1994). Stories of unexpected life paths are often consistent with findings generated by studies of specific outcomes in groups of high-risk children. By pursuing predictors of good outcomes, these correlational and multiple regression analyses shed light on protective factors that might lead to such outcomes (Figure 1).

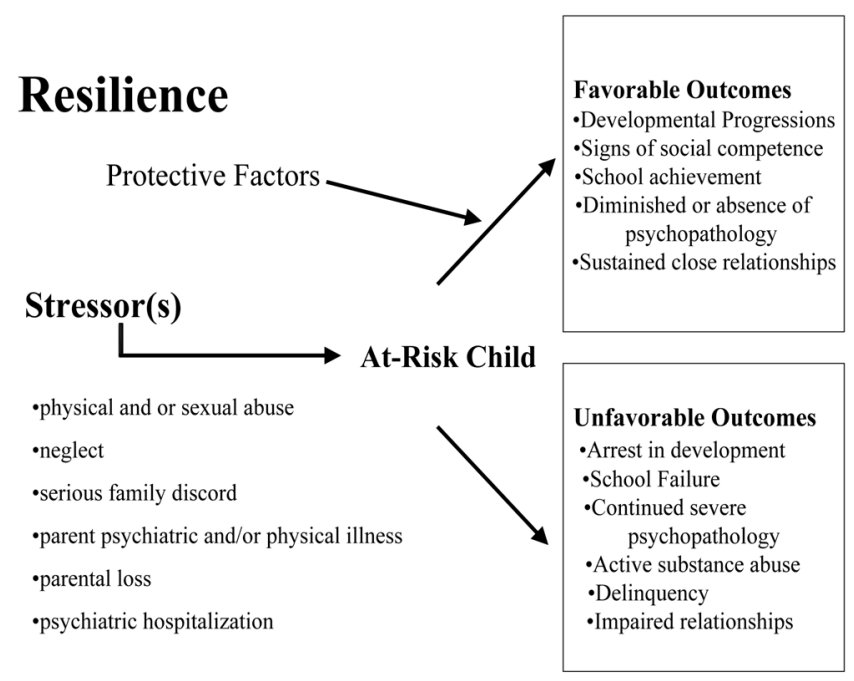

Figure 1

2) Good individual adaptation despite adverse events, experiences of misfortune. Sometimes these studies of specific individuals focus on a presumed serious challenge, such as parental divorce. Other investigators target the composite of heterogeneous adverse experiences during a 
specific time period in development, like adolescence. Yet a third variation is where one traces the individual's early responses and subsequent development following a particular misfortune, like the early loss of a parent, serious parental illness, sustained poverty. This second perspective leads to an individual life trajectory approach.

3) Individual differences in recovering from trauma. Traumatic experiences represent adversities of great severity, with acute onset or chronic repetition (as in child abuse), going well beyond the challenges normally faced in development. Traumatic events or experiences may be natural ones, as in floods or earthquakes; or created by human design, as in war or torture. By their very nature, traumatic experiences are expected to reduce the quality of functioning. In the case of these extreme or life threatening stressors, resilience refers to patterns of recovery (Figure 2).

\section{Resilience: Individual lives and trauma}

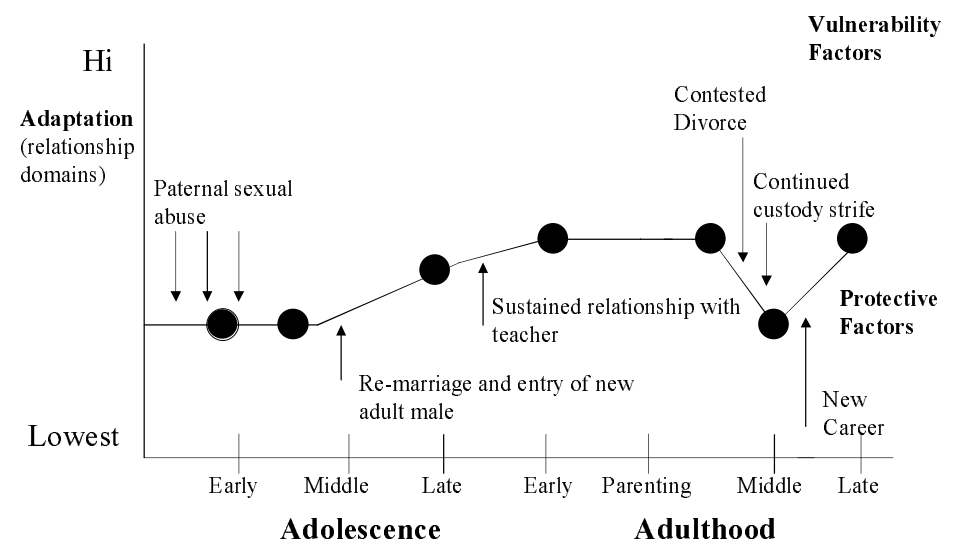

Figure 2

Besides illustrating the third view of resilience, this composite trajectory conveys the idea that an individual's resilience changes over the life course. In our work we use person-based approaches, what Luthar and Cushing (1999) call "individual-based measurement" (also, cf. Gjerde, Chang \& Kremen 1998). Person-based approaches contrast with variable-based strategies. In variable-based analyses, one follows an (often large) sample of participants presumed exposed to adversity, but 
missing is specific information on the degree of exposure and experience of each individual to the hypothesized risk factors in such an overall high-risk sample. Consequently, we do not know which individuals within a particular sample actually meet the definition of resilience, specifying both high risk and high competence (Table 2; Luthar, Cicchetti \& Becker 2000). For all three classes of resilience phenomena, authors generally define resilience in terms of successful adaptation despite challenging or threatening circumstances. This adaptation usually includes internal states of well-being, effective functioning in the environment, or both (Masten et al. 1990, p. 426). The definition of resilient development underlying our studies described below is based on the contemporary one delineated by Luthar and colleagues (2000), refers to internal states as well as observed behaviors.

Table 2. Resilience (Luthar, Cicchetti \& Becker 2000)

- Resilience refers to a dynamic process encompassing positive adaptation within the context of significant adversity.

- Implicit within this definition are two critical conditions

- $\quad$ Exposure to significant threat or severe adversity; and

- 2 . The achievement of positive adaptation despite major assaults on developmental processes.

Protective factors are key constructs within theoretical and empirical studies of resilience. These dimensions moderate the effects of individual vulnerabilities or environmental hazards, so that a given developmental trajectory reflects more adaptation in a particular domain than would be the case if protective processes were not operating. Longitudinal and cross-sectional studies have illuminated protective factors from several domains. Tables $3 \& 4$, synthesized from Masten (1996), Vaillant (1993), Rutter (1987), and Werner (1996; Werner \& Smith 1992), summarize processes conceptualized as fostering resilience. 


\begin{tabular}{|c|c|}
\hline Table 3. Protective Factors (1) & \\
\hline \begin{tabular}{ll} 
& \multicolumn{1}{c}{ Individual } \\
- & Attributional Style \\
- & Temperament \\
- & *Good intellectual skills \\
- & *Appeal to others, especially \\
- & adults \\
*Ability to internalize social \\
- & *Apports \\
-Arena of talent or perform- \\
- & ance valued by self or others \\
- & *Self-efficacy, Self-esteem
\end{tabular} & $\begin{array}{ll} & \text { Relational (including family) } \\
\text { - } & \text { Effective parenting } \\
\text { - } & \text { * Supportive home environ- } \\
\text { - } & \text { ment } \\
\text { - } & \text { connections to other } \\
\text { - } & \text { *Positive relationships with } \\
& \text { extended } \\
& \\
& (*=\text { narrative data relevant) }\end{array}$ \\
\hline
\end{tabular}

\begin{tabular}{|c|c|}
\hline $\begin{array}{l}\text { Community } \\
\text { - *Religious Faith or affiliation } \\
\text { - *Good schools and other commu- } \\
\text { nity assets (e.g., clubs, } \\
\text { teams)Socioeconomic advantage }\end{array}$ & $\begin{array}{l}\text { General } \\
\text { - } \quad \text { *Good fortune } \\
\text { * } \quad \text { *Timing } \\
\quad(* \text { = narrative data relevant })\end{array}$ \\
\hline
\end{tabular}

Our overarching goal is to more fully understand how resilient development unfolds. Through a person-based approach, guided by a follow-back design (Figure 3), we analyze previously recorded adolescent and adult interviews of now competent young adults who experienced significant adversity during their adolescent years. As teenagers, they encountered three serious misfortunes. These young adults were psychiatrically hospitalized from two months to two years during their middle adolescence. Among the consequences of this hospitalization were: First, an abrupt separation from their families, friends and communities. And second, experiencing a serious psychiatric disorder leading to hospitalization, regardless of how time-limited, can markedly change the experience of self, often leading to lowered self regard and lowered perceived personal competence (Cohler et al. 1995). The label of psy- 
chiatric patient is made even more indelible by psychiatric hospitalization. The third serious misfortune was trauma. Several of these young adults, now functioning in highly competent ways, reported serious child and adolescent physical abuse at the hands of immediate family members or other close relatives.

As we now study these resilient young adults, we consider individual and interpersonal characteristics that may have acted as protective factors in their lives. Using their narratives, drawn from annual clinical interviews in adolescence, we are locating formal and thematic components found in the adolescent discourse of young adults who followed resilient trajectories. While our findings can be most precisely understood as representing individual protective processes, the reciprocal connection between individual and relational protective factors suggests that these narratives will also reveal how the adolescents and young adults recruited, sustained, and experienced relationships. In short, our quest to account for young resilient outcomes is drawing upon new analyses of individual narratives expressed over a 20 -year period.

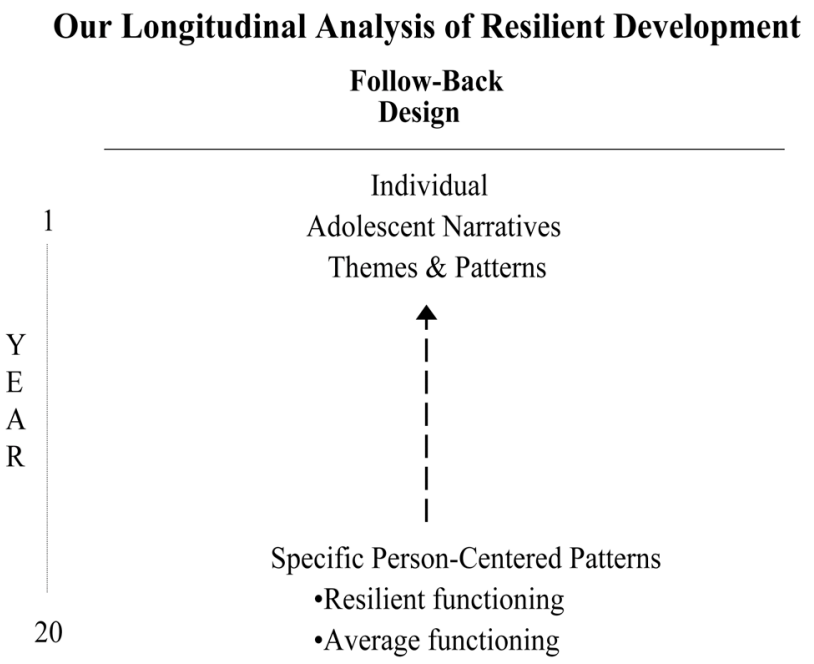

Figure 3 


\section{I begin with Eve':}

I know I could try. But I know if I try I know how to go back... In between you can go up or you can go down. And if you go up and somebody pushes you down, you're gonna be bummed. And if you go down and nobody helps you back up, you're gonna be bummed. So you should just sit in the middle for now, just see how things work out. And if I feel like I'm gonna talk, I'm gonna. If I don't feel like it, then I'm gonna sink down. Right now I'm sinking. But I think I might be able to work things out.

As a 14-year old, Eve is thinking aloud about changing, a year after slashing her forehead and heavily abusing drugs. Sixteen years later, now a mother of three very young children, she tells about her struggles as a parent:

I'm a good parent... When the kids were younger, I always used to like arts and crafts with them.... And then I ... went back to work. Before I would do a lot of stuff with them, and now it's more like "just find something for yourself to do"..... Once in a while I'll get feeling real guilty, and now I'm gonna do something with my kids and I don't care if the house is falling apart. Then so be it. I'm going to do something and we'll go out... We'll sit there and I'll make picnic lunches and we'll get a blanket. And we'll lay on the grass before I've got to go to work.

A decade after first meeting Eve, we discovered that she and eight other young men and women, seriously disturbed during their teenage years, were now leading competent and productive lives. As adolescents they experienced a remarkable derailment. Usually by surprise, they were suddenly admitted to a psychiatric hospital. Separated from their families, in new bewildering surroundings they had to respond to unfamiliar adults whom they never asked to be their caretakers, and attend a

${ }^{1}$ All names of subjects in this paper are not their actual names. In addition, to protect confidentiality, other possible identifying information such as hospital names or locations, are also changed. 
special school they found repugnant. Picture these young adolescents: already seriously troubled, they were now thrust into a new disturbing neighborhood, a large hospital community, and a new school; they were forced to contend with many frightening peers, classmates, and adults. How did these teenage boys and girls make sense of this unexpected long stay at High Meadows, a hospital not of their choosing? And now, almost two decades later, how do these young men and women understand their time in the hospital and what happened since their departure?

3.

Our longitudinal resilience project takes up these and related questions (Figure 4). In 1976, we began meeting with 146 middle adolescents and their families (Hauser 1991b).

\section{Longitudinal Design of Young Adult Phase: Resilient Functioning Project}

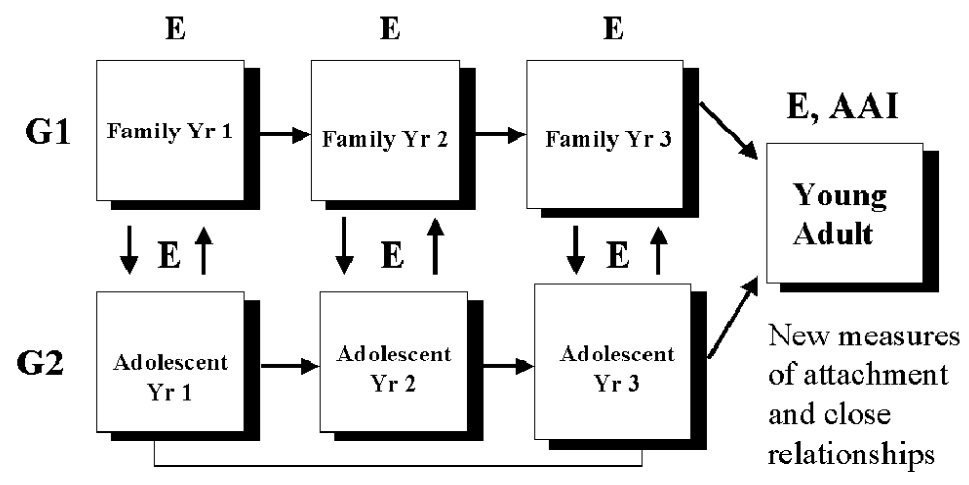

Adolescent Ego Development Trajectories

Figure 4

Our sample was drawn from two groups: non-psychotic patients from a private medical school teaching hospital, and volunteers from the freshman class of a local high school (Table 5). The patients included three major diagnostic groups: disruptive behavior disorders, mood disorders, and personality disorders. We excluded psychotic patients, those 
with evidence of mental retardation, or with medical conditions associated with psychiatric sequelae. The patient and high school samples were comparable in age, race, and family type (one-parent and twoparent); they were predominantly white middle and upper-middle class.

\begin{tabular}{|l|c|c|c|}
\hline \multicolumn{4}{|l|}{ Table 5. Original Adolescent Sample } \\
\hline & Male & Female & Total \\
\hline Psychiatric & 39 & 31 & 70 \\
\hline High School & 34 & 42 & 76 \\
\hline
\end{tabular}

Over successive adolescent years, we continued to meet with 85 percent of these adolescents and their families. The adolescent participants responded to specific developmental and personality measures, and participated in annual clinical research interviews usually with the same clinically trained interviewer (Table 6). During these one to two hour clinical research interviews participants were encouraged to associatively respond to inquiries about family and individual history, peer and family experience, school life, emotion regulation, and visions of the future.

Table 6. Adolescense: Annual Assesments

1. Ego Development (SCT)

2. Adaptive strengths and defenses (Clinical research interview and coping scales)

3. Emotion Expression (Clinical research interview and AECS)

4. Narrative accounts of self-themes, relationships, and resolutions (Clinical research interview and Readers' Guide)

5. Self-image integration and continuity (Self-image Q-sort)

6. Self-esteem (Coopersmith self-esteem inventory)

In previous analyses we've used the tapes and transcriptions of these interviews to assess defenses, self-images, and emotion expression (e.g., Hauser, Borman et al. 1991; Hauser, Powers et al. 1983; Safyer \& Hauser 1994). Now we're examining our original participants' interviews in a new way, looking closely at the stories they told over four adolescent years and one young adult year.

Eleven years ago, we located all of the former high and low-risk adolescents, and met with 97.3 percent of those young adults still alive (Table 7). 


\begin{tabular}{|l|c|c|c|}
\hline \multicolumn{4}{|l|}{ Table 7. Young Adult Sample } \\
\hline & Male & Female & Total \\
\hline Former Psychiatric & 37 & 29 & 66 \\
\hline Former High School & 34 & 42 & 76 \\
\hline
\end{tabular}

In this new phase, using a range of measures conceptually relevant to young adult tasks, we assessed the participants' ego development, close relationships, attachment representations, and several aspects of social competence (Table 8). Many of our participants were beginning new families, alerting us to the opportunity for extending our longitudinal program to study marriage and parenting in a third generation.

Table 8. Dimensions Used to Identify Resilient Young Adult Functioning

1. Ego Development

2. Quality of Peer Interactions (perceived by friend)

3. Close Peer Relationships

4. Adult Attachment Representation Coherence

5. Social Competence: Criminal Behavior, Substance Abuse \& Psychiatric Symptoms

After meeting with the young adults, several interviewers were astonished when the person whom they had been speaking with for the past couple of hours suddenly told them (almost always toward the end of the interview) about their disrupted adolescence, about how they had lived many months or several years in a psychiatric hospital. Our interviewers' amazement was especially meaningful, since they were deliberately not given any information about the histories of anyone with whom they were meeting. ${ }^{2}$ These surprises led to our new questions and curiosity about resilience.

What was it about these young adults that surprised the interviewers? Interviewing our interviewers and exploring the resilience literature led to our conceptualizing resilient young adult development in terms of individual outcome profiles, encompassing ego development, close relationship functioning, and social competence. We translated this concep-

${ }^{2}$ One exception to this practice was when interviewers were scheduled to meet with former patients who were now in prison. The young woman or man who might interview the prisoner were now told of his psychiatric history (all were males), and given the option of declining the assignment for that interview. No interviewers refused to meet with any of these former patients. 
tual definition into an empirical one. What's most important is that through this definition we could systematically identify those young adults whom we classify as resilient. Having located this special group, we then used a narrative approach to intensively study the adolescent experience of each participant, thereby tackling the question of whether there were clues in their narratives - between ages 14 and 18 - that might have predicted which boys and girls would later show resilient outcomes. In other words, we followed a group of resilient young adults - back to their adolescent years (Figure 3).

Our initial challenge was to operationalize what we thought the interviewers were seeing. We first identified former patients with development and relationship scores above the $50^{\text {th }}$ percentile for the entire sample, which includes both non-patient and patient participants. We used four measures: ego resiliency as judged by friends (Kobak \& Sceery 1988), relationship closeness (Berscheid 1987), attachment representation coherence (Main \& Goldwynn 1998), and ego development (Loevinger 1976) (Table 9).

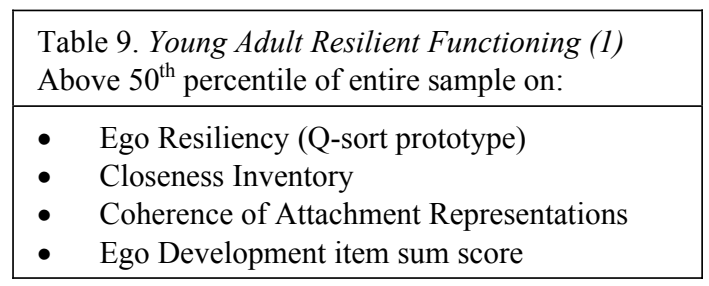

We then considered social deviance and psychopathology. To be identified as highly competent on these measures, former patients must have scores below the $50^{\text {th }}$ percentile for the entire sample. We used three indices here: hard drug use in the past six months (Elliot et al. 1983), criminal behavior in the past six months (Elliot et al. 1983), and global psychiatric symptoms (Derogatis 1983) (Table 10).

\begin{tabular}{|l|}
\hline $\begin{array}{l}\text { Table 10. Young Adult Resilient Functioning (2) } \\
\text { Below } 50^{\text {th }} \text { percentile of entire sample on: }\end{array}$ \\
\hline - $\quad$ Hopkins Symptom Checklist \\
- Delinquency/Crime Questionnaire \\
- $\quad$ Substance Abuse Questionnaire \\
\hline
\end{tabular}

Four men and five women, thirteen percent of the 67 former patients, fit this profile definition of young adult resilience. 
Having identified the young adult resilient subjects, we could now through our follow-back design - examine our years of adolescent and adult observations. Available to us were data generated by a panoply of methods, encompassing semi-structured interviews, self-report questionnaires and systematically coded observed family interactions. Instead, we chose a new point of departure: the complex and resonant personal narratives embedded within the many hours of each subject's adolescent and young adult interviews. Through new detailed studies we expected to discover previously uncharted individual and relational protective processes. Because we planned to follow, for each subject, up to eight interviews over two developmental eras, we would also be positioned to probe yet another compelling question: Does the nature and effectiveness of protective processes change over the life course for resilient and less resilient subjects?

4.

Gay Becker (1997) describes narratives as the stories people tell about themselves, reflecting people's experience as they see it and as they wish to have others see it. "Through stories people organize, display and work through their experiences." She further argues that "narratives can be a potent force in mediating disruption, whether the disruption is caused by illness or personal misfortune" (Becker 1997, p. 25). Through narrative analyses we can begin to grasp how individuals create and maintain coherence over time. Rita Charon extends these ideas in her recent writing about narrative medicine. In her words,

"As patient meets physician, a conversation ensues. A story - a state of affairs or a set of events is recounted - by the patient in his or her acts of narrating, resulting in a complicated narrative of illness told in words, gestures, physical findings, and silences and burdened not only with the objective information about the illness but also with the fears, hopes and implications associated with it. As in psychoanalysis, in all of medical practice the narrating of the patient's story is a therapeutically central act, because to find words to contain the disorder and its attendant worries gives shape to and control over the chaos of illness." (Charon 2001, p. 1898)

Narrative approaches have a long history in the social sciences and psychoanalysis. Within psychoanalysis, Schaefer (1992) and Spence 
(1982) use narrative frameworks in their considerations of psychoanalytic dialog, constructions and epistemology. Besides Becker and Charon, influencing the narrative methods we're developing are contributions by Bruner (1990, 1994), Mishler (1995), Gilligan (Brown \& Gilligan 1992), Lewis (1997), Main (Main \& Goldwyn 1998), Reissman (1993), and Cohler (e.g., Cohler, Stott \& Musick 1995).

Based on our reading of the resilience and adult attachment literatures, and many reviews of the adolescent interviews, we created a Guide for analyzing narratives within the open-ended interviews 3 . Our guide alerts the narrative analyst to content areas and structural features likely relevant to resilient outcomes. We begin by demarcating two stories, the patient's path to the hospital and his or her life within the hospital. These stories are extracted from all of the first year interviews (Table 11). Important formal aspects of these and subsequent key stories are coherence and passivity or vagueness in discourse (Main \& Goldwyn 1998). Thematic components of interest include representations of self and of interpersonal relationships. With respect to self (Table 11), we consider ways of disclosure and privacy, self-reflection, agency, selfefficacy, self-esteem, aspirations, helplessness, and long-term visions. Representations of relationships (Table 11) include the extent to which the person speaks about them as interconnected; how he or she seeks, recruits, and maintains ties with others.

Noteworthy is the fact that we do not intend our guide to be a constrained coding system, a rigid template forcing categories onto these rich texts. Rather, our guide is designed to sensitize the reader to important clusters of themes, while encouraging openness to seeing novel patterns within the interview discourse. After the hospital year (Table 11), we continue to analyze subsequent year's interviews, using the same guide. Now the questions are applied to new stories about current life and self-described changes. But when a participant brings up his path to High Meadows and to his life there, we pay close attention, since we expect that this revisiting may shed new light on the changing ways resilient adolescents made sense of an extraordinary time in their lives.

\footnotetext{
${ }^{3}$ The ideas for this guide were strongly influenced by the work of Brown and Gilligan (1992) and Main and Goldwyn (1998).
} 


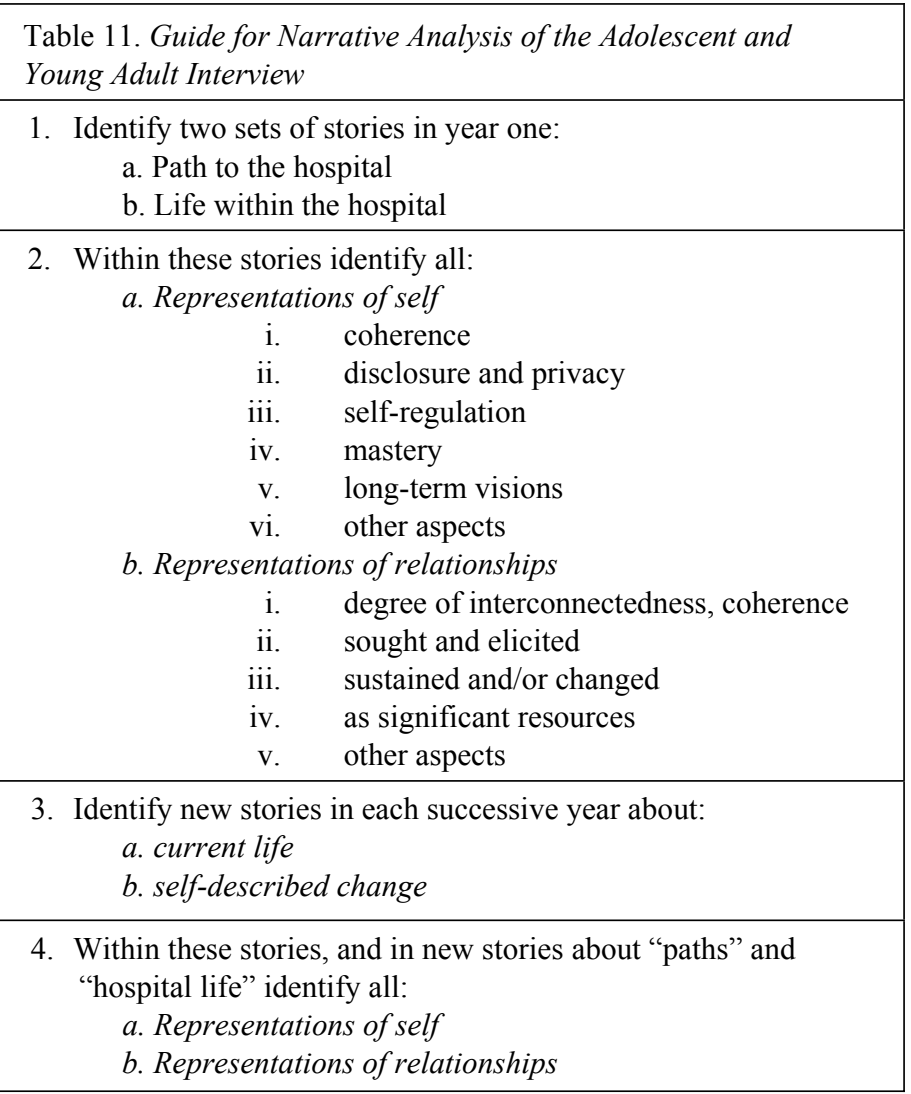

Since I believe that it is through following individual lives over time that we can gain the strongest insights from our narrative analyses, let's return to Eve, tracing her narratives of parenting first as an adolescent (having parents) and then as a young adult (being a parent).

\section{1. EVE}

Restless and desperate at school and at home, Eve was admitted to High Meadows Hospital at age 13, acutely confused, with disorganized behavior, and self-mutilation. For years, Eve expressed mounting disappointment about her parents. Although she first described her father as supportive, in all later years she portrayed him as severe, dogged, angry, and disrespectful. She felt deeply troubled by him, in two ways. 
My father gave up trying... He told me no matter what, he would never give up.... He let me down and he let himself down ... I knew all the time my father was going to give up.... And it wasn't a shock to me.... It's like you are waiting for someone to die. When they die, you know.

The second way was by consistently telling her how bad her thinking and friends were, stubbornly insisting that she's an "asshole". “.... [I'm] getting to the point I'm not gonna care. I am gonna end up being a jerk - I'll probably go away."

Yet sometimes, while anguished over her father's verbal abuse and her mother's passive agreement with the abuse, Eve at the same time reflects about them:

...they always blamed their problems on us. We could be a little bit of the cause... But they didn't have to do half the shit they did. The choice was theirs.

Similarly, Eve recognizes that it's her own choice to "do anything wrong"...

Because I know what's right and wrong... I'll just make decisions for myself... and if it turns out that I'm an asshole by making a decision instead of him, then that's tough luck... I found out the only person who could fix things is me... If I mess up, at least I will know it's my fault.

Within Eve's reflections about herself is an important quality - recognizing her responsibility for her thoughts and actions, what Bakan (1966) terms human "agency".

In late adolescence, Eve describes more peaceful times with her parents, now liking her mother "better", and not talking to her father because he makes her too uncomfortable. In great detail, she characterizes his fixed ideas; in any discussion with him he "always comes back with his opinion and his opinion would always have to be right... whatever he says goes." What's now fostering greater harmony within the family is Eve's not confronting him by yelling at him. "I'll say [to him] this is what I want to do." Seeing she's like her father in being "dead set against things," is a new insight she has in her last adolescent interview.

Seven years later, when we meet Eve as a young adult, she portrays more complex pictures of both parents and continues to speak about themes she expressed in her adolescent narratives. Her mother, as Eve looks back on child and adolescent years, was giving, caring, and under- 
standing. These are clearly more positive attributes than ever appeared in Eve's adolescent narratives. Yet Eve recalls how confused her mother was, "because she didn't know what to do," and how mad she was, because "she was stuck in the house all day with her three children, unable to go out and find a job or return to school."

Eve's young adult narrative of her father first appears more generous - fun loving, caring, kind. In a few moments, her more ominous image appears:

He had a mental way of working on you, [making you] feel....you were worthless...he'd put you down about everything you did...If you cared about your friends, he'd say, "your friends are a piece of garbage," and to us they were important... No physical abuse...just threats...

Now a parent of three children under five years old, Eve describes her almost automatic reaction of quickly closing down and not listening, the moment she senses her father is about to criticize her, to get in one of his states where, "... he's being so ignorant about being not able to budge either way in understanding where you're coming from."

As she looks back, Eve's strongest regrets about her father remain: That he couldn't see where she was "coming from", and not intimidate her. While some of her constructions of him have become more nuanced and positive, her powerful awareness of his stubbornness and verbal abuse persist, presenting constant dangers to her growing sense of confidence and well-being.

Unhappily, Eve tells us about her second child. She sees her fouryear old son, Bobby, as "more like his dad, because he's real slow." And not only is he slow, "it's like he's not trying... He gives up more... He'll go back one day and finally get it." Added to his slowness and lack of persistence is his stubbornness, short attention span and provocative temper tantrums. Echoing her experience of pervasive criticism by her father are Eve's strong and many-sided disappointments with Bobby.

Eve refuses to tolerate Bobby's weaknesses. She believes her attitude will help him know that other people are not going to tolerate his limitations either. Her father and husband converge, as she describes her husband as looking at things "like either it's right or wrong and that's not it." In contrast, Eve is proud of her propensity to step back, and think about there being

...different ways, different perspectives and depending on...the way 
you are in life,...things change so you can't always be contradicting things or criticizing things. You have to be more of an open-minded type. I got that from my teenage years.

Finally, Eve believes that one of her most serious limitations is her reluctance to strongly discipline Bobby. Her parents were also reluctant, and her father still regrets not beating her. She has Bobby go to the corner, take time out, hold his breath. Similar to her parents, who "didn't hit us much," Eve does not want to punish her children in "heavy duty" ways.

Along the lines of content (discipline, specific child criticism of stubbornness, and lack of persistence) and style (being reflective, taking responsibility), we see Eve expressing - over a decade later - varied continuities from her adolescent narratives. Yet we also find signs of change, in terms of her more multifaceted and forgiving descriptions of her parents.

Sharply differing from Eve, Pam and Jenny - average outcome patients - speak in limited ways about their new parenting experiences. Only occasionally do they speak of their own parents. Both young women are having great difficulty as parents - Jenny has lost custody of her only daughter; and Pam is tired of her several marriages and of having children each year. These average outcome former patients tell us of unstable marriages, together with barely decipherable connections with adolescent parenting images. Their stories are stark, portraying great loneliness, few signs of agency or hopes for change, and few relationships.

\section{2. PETE}

A second resilient young adult arrived at High Meadows after 12 public and private school expulsions, where his explosive violence made him almost instantly unwelcome in each new setting. Yet with unusual ease for a fourteen-year-old, Pete tells new adults at High Meadows about a family life replete with threats, tempers, and sudden physical brawls. His abusive relationship with his father was a model, from early times, for volatile destructive episodes with others. Pete witnessed seemingly uncontrolled abuse between his father and his siblings, recalling scant protection from his mother. And when his father was drunk, these experiences and the aftermath of regrets were even more dreadful. In the midst of these most turbulent and troubled adolescent years, we 
hear Pete's lively inner conversations about troubled relationships and desires. He needs friends, desperately at times. And each friend frightens him. Guided by his formidable talent in sizing up himself and others, Pete recruits various adults - whom he calls his 'mentors' - to be his companions. This recruiting talent is one of his greatest assets.

Just before coming to High Meadows, Pete makes his fury towards his father more visible and frightening. Stealing his grandfather's gun, he sends a message to his father. "I didn't tell him directly. But I'm sure he had heard about it. Cause I told enough of his friends and enough of his relatives that I'd kill him if he touched me again." Now a young teenager, Pete has discovered a way to control his father's blazing rage: directly and indirectly threatening his life. Pete now recruits a new mentor, Bob Jenkins, a school social worker, to whom he reveals both his hatred of his father and how terrified he is about carrying out his deadly threat.

One time it got so bad and I couldn't hack it any more. And I just went to [this friend] who worked at the school. I said, "You gotta do something...put me anywhere, but away from him. [his father]"... I had a lot of [other worries] too...like my walking a younger kid into the park at knife-point. That's why I went to the emergency care shelter, cause everything was driving me crazy, and I would have killed myself.

During his two years at High Meadows Peter makes much progress in controlling his fury. And then he faces many setbacks: close relationships ending; disappointment and discouragement at an acting school where he imagined becoming a great star; and the threat of alienation from his mother, the most powerful and revered adult in his life. With these accumulating reversals, Pete decides to leave the "state". Under a false identity, he travels across the country, stopping himself from making any strong new relationships. After one year, he returns home, once again valuing relationships.

Let's fast-forward seven years. Pete has now graduated from a major research university, is a writer, and has his first full-time adult job in a computer firm. And he has found a new close friend, Arnie, with whom he lives and travels from late adolescence through his young adult years. Alongside intermittent intense disruptions in their relationship, Pete experiences Arnie as a caring devoted older friend, one more important man is the line of his older male friends, mentors he's been recruiting since before high school: 
These were all mentors. These were all the people who had a lot of bearing, a lot of influence on my life. And I know it sounds weird. I don't have a lot of friends my age... I guess I was replacing my father like 10 times over.

In their ten-year stormy friendship, Arnie and Pete have traveled together all over the world. Between trips Arnie rescues Pete from urgent situations, like bailing teenage Pete out of jail after big public fights or drug busts. Over the years they talk about their loneliness, about Pete's becoming "tongue tied" in close relationships with girls. They have intense arguments in airports and on trips, usually triggered by Arnie's jealousy over Pete's new sexual flirtations; or by Pete's idea that Arnie is "playing games" with him, threatening by innuendo or not saying what's really on his mind. Arnie points out to Pete times when he's withdrawing, becoming one more voice pressing Pete to think about his "barriers".

...[Arnie's] one of the people who accuses me of having emotional barriers. And he always wants our friendship to get even deeper, as emotionally. He's not coming on to me... But he always says I keep a barrier, just a certain distance. And it pisses him off.... I was brought up like that. Because my mother was a little like that... My grandfather was a little like this. So he feels it.... He's from a very warm Italian family...people love and hug and cry together. And, Jesus, that just doesn't happen in my family...

Pete's perception of his and Arnie's very different backgrounds can't fully explain the vacillating closeness and distance he experiences in other relationships. He also sees his exquisite fear of being hurt by others leading him to jump back, cut off, and then slowly return to the other person. More clearly becoming aware of his fears over being abused, submitting, and surrendering, is what Pete's referring to when declaring that he's grown emotionally through friendships and "tons and tons and scads of therapy...and I worked very hard to work myself out... I had more support somewhere." The tension between his appreciating the importance of close friends and his difficulties tolerating close relationships is the central dilemma of Pete's young adult years.

So why, as I describe these continued internal and interpersonal struggles, do I also tell you that Pete represents a resilient former patient father and stepfather. In fact, marking Pete's psychological development 
is the radical change in his relationship with his stepfather. Once called a sub-human 'computer' with no feelings, a man whose 62-year-old bones Pete wanted to crush, he has now come to be a valued friend. At age 35 Pete told me he was going to Europe to take a bike trip across Belgium with him. I asked him if this was the same stepfather he spoke about in teenage days. And he said, "Oh yes. I've really changed; now we're close friends." Pete illustrates well the idea that resilience is not a monolithic unchanging trait within a person. It is a dynamic patterning of strengths and sensitivities responsive to age and context. This profile of an individual's resilient features changes over the life cycle with respect to its salient dimensions.

5.

Through new narrative analyses of these resilient young adults, we're becoming aware of experiences of self and of relationships that simply weren't tapped through previous empirical procedures. For instance, our more traditional analyses were theory-driven and constrained by rigorous coding conventions and technical language as we were pursuing indices of defenses, adaptive strengths, self-images, expressed effects, and enabling interactions. In working with our previous methods, we often had the impression that we were not capturing significant aspects of the subject's experience; especially their vividly described the poignant past and current relationships. And when our coders would bring up these limitations, we'd usually speak - somewhat dismissively - about the compromises forced upon us by systematic empirical research; how we could not possibly study all the unique features embodied in one subject's interview. But our coders were, in hindsight, obviously correct in pointing out a meaningful problem. Their concerns had to do with at least two issues. First, the units we were analyzing were too constricted. Fuller portions of text are required to locate certain nuances of form and meaning. Second, we focused on categories derived from theoretical perspectives we believed relevant to testing our hypotheses. In other words, we were not identifying personal meanings, ways a subject was making sense of his or her world. Verghese (2001) speaks of this problem: "Any professional language brings with it the risk that it will also put blinders on us, bring about an atrophy of our imagination, a waning of the ability to understand the suffering of the patient." (Verghese 2001, p. 1015) These concerns led to our construct- 
ing a new kind of analytic procedure, our Guide? Across several domains - ego development, attachment coherence, substance abuse, emotion regulation -25 year old Pete is stunningly different from 16 year old Pete, a bereft and furious boy, rushing to leave the state; a teenage boy with violent maiming fantasies about his for Interview Texts, designed to systematically and reliably extract structural and content dimensions from our semi-structured adolescent and adult interviews.

Based on these explorations, we think there are strong reasons to add narrative analyses to our ongoing life span studies. From our examination of more than 60 adolescent and adult-interviews from the resilient and average outcome young adults - spanning over 20 years we have a better grasp of resilient participants' constructions of themselves and their relationships during a time of major disruption; and we have seen ways these constructions change over time. In terms of constructions of self, we have found five content themes and one structural feature (Table 12):

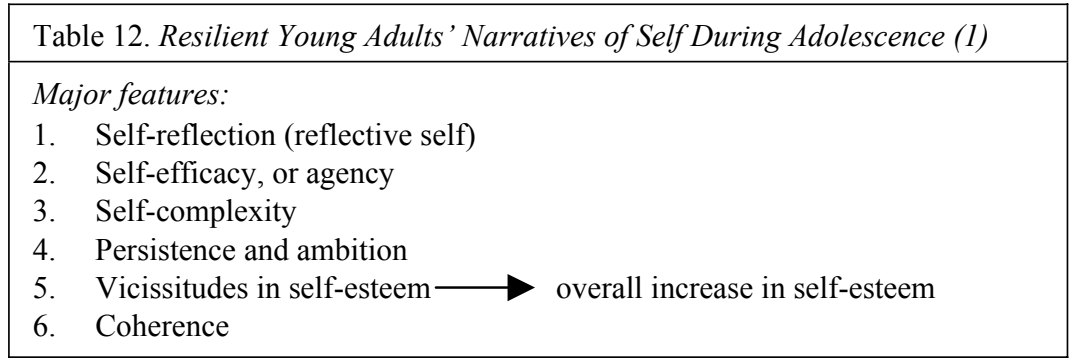

1. Self-reflection, illustrated by individuals' increasing awareness of their feelings and thoughts, within each adolescent year and in later thinking about their experience and performance as adults and new parents. A few weeks after entering High Meadows Pete was stunned right after grabbing Joey, another student annoying him at school: “... I stopped about that close to his face. And I said [to myself], 'What am I doing?... What the hell am I doing?'.. that's not like me any more, to jump up and take that extreme. I usually say something before [I get totally furious] and they'll stop."

2. Agency. As adolescents, the resilient patients played an active part in deciding where they would go after leaving High Meadows and how they would take care of themselves when again in trouble. Sandy admitted herself to a community hospital, two years after leaving High Meadows, when she couldn't stop taking 'uppers' and 'downers.' Pete left the 
state in order to disrupt the destructive cycles which threatened his maintaining relationships with his mother and friends. As adults, they make conscious choices about parenting and how to put their ideas into practice - recall Eve and her picnics. Related to this theme are the resilient adults' detailed visions of their future, and their conscious plans to make sure they actualize these optimistic dreams.

3. Self-complexity. We've seen this feature in Eve's recognition of her many sides. Pete speaks of his complexity as he many times tells us about his multiple worlds - his tough biker pals, his concert crowd. We've found evidence of complex continuities over time, the resilient subjects' recognizing parenting themes from their past; they embrace their discovery of multiple perspectives about themselves, and about their friends.

4. Persistence and ambition. Resilient patients describe a refusal to settle for a specific solution offered by a hospital, a therapist, or their family. Several find new schools. Two years after her discharge, Sandy arranges for admission to a community psychiatric facility to help her with a new drug problem, and then discharges herself when she thinks the problem is solved. Others return to complete training many years after interruptions.

5. Self-esteem. Ever apparent are the resilient participants' vacillating appraisals of themselves. By no means were these evaluations simply increasingly positive over the years. As we've seen with Pete, they were marked by swings of confidence as well as disappointment, optimism and pessimism about life's chances. Important was their awareness of these self-evaluations, and the overall balance tipping in the direction of kinder self-regard each year.

6. These are coherent narratives. From the start, we were struck by the ease of discerning the resilient subjects' stories - first about their paths to High Meadows, then about their experiences there. In subsequent years, they provide coherent accounts of their lives, conveying personal successes and failures, and new views of their hospital experience. Sometimes their "ups and downs" are breathtaking and turbulent. Yet the interviewer, and later the reader, can grasp the alternating disappointments and successes. Changes, and connections to the past were often the very first things a resilient subject talked about each year when he or she met with their interviewer. Audiences hearing their stories are often touched by the alternating disappointments and successes.

Turning to constructions of relationships, we see three themes (Table 13): the resilient adolescents do much reflecting about others' mo- 
tives, feelings, and thoughts. Second, the resilient individuals attribute great importance to close friendships and have a thirst for friendships. They tell us about recruiting relationships. They do not imagine simply meeting people by chance. They tell us of how they find new friends and how these friends help in their recovery from disrupted teenage years. Recruiting and retaining mentors was a crucial theme through Pete's adolescent and young adult years. The special significance of relationships further unfolds in adulthood, as the resilient participants speak of their new spouses and about parenting with their spouses. Finally, the resilient individuals see many intersections among themselves, their relationships, and their actions; speaking, for instance, about how growing good feelings about themselves are leading to more positive ways they're seeking and respecting new friends.

Table 13. Resilient Young Adults' Narratives of Relationships During Adolescence (2)

Major features:

1. Reflection about others' motives, feelings, and thoughts ("psychological mindedness")

2. Friends and other close relationships as key resources to maintain and invest in

3. acknowledged intersections among self-representations, relationships, and actions.

In the long run, what can we gain from narrative analyses of sequential adolescent and adult interviews? One key benefit can be greater understanding of how these adolescents' narratives contributed to their subsequent adult development. For example, we could hypothesize that an adolescent's increasing narrative complexity and coherence may herald signs of psychological health in adult years. An additional intriguing possibility is that adolescent patients' conscious recognition of personal change predicts ongoing and subsequent adaptations. As we think about direction of influence, it's important to recognize the strong possibility that causal paths may not necessarily move from narratives to outcomes. These narratives could be markers, reflecting changing life circumstances and optimism, leading to change in narrative understanding; and then to new impacts from the narratives themselves, to actions, as the resilient participant makes plans - like future families and having children. 
Through longitudinal interview analyses of these nine resilient patients, alongside parallel analyses of average outcome patients, we can begin to delineate some of these complex causal chains. For instance, our first analyses of average outcome patients suggest that they experienced greater helplessness, rage, and diminished self-esteem as adolescents. Fewer steadily supportive and protective relationships with friends and family were available. Nor did these participants consistently recruit relationships. Their adult marital relationships are volatile. Parenting is neither easy nor cherished. As we identify these contrasting themes, we will take the next step of defining new variables - like reflectiveness, agency, relationship recruiting - for which we will systematically search in the adolescent and adult interviews. We can begin to specify how these narratives may shape important adult outcomes including close relationships, parenting, and psychopathology.

Understandings generated by this new way of looking at our data should also shed light on how these patients adapted to trying circumstances during a most turbulent adolescence. Tracing the flow of meanings constructed by adolescents and young adults can lead to our locating new individual and relational protective factors. Formal characteristics of their teen-age narratives, like increasing coherence and diminished passive discourse, may be among the special features that distinguish the resilient young adults from the other former patients. Through such developing strengths, these adolescents may have compensated for serious psychopathology and adverse hospital and home circumstances, as well as capitalized on available resources -psychotherapy, special teachers, friends, and schools. Our other instruments may not be attuned to the subtle manifestations of these strengths. We are taking this narrative turn to see how personal meaning and meaning-making can foster unexpected pathways from adolescent misfortune to young adult competence in friendship, marriage, and parenting. 


\section{REFERENCES}

Bakan, D. (1966). The Duality of Human Existence. Boston: Beacon Press.

Beardslee, W.B. \& Podorefsky, D. (1988). Resilient adolescents whose parents have serious affective and other psychiatric disorders: Importance of selfunderstanding and relationships. American Journal of Psychiatry 145: 63-69.

Becker, G. (1997). Disrupted Lives: How People Create Meaning in a Chaotic World. Berkeley: University of California Press.

Berscheid, E., Snyder, M. \& Omoto, A.M. (1987). The relationship closeness inventory: Assessing the closeness of interpersonal relationships. Journal of Personality and Social Psychology 57(5): 792-807.

Brown, L. \& Gilligan, C. (1992). Meeting at the Crossroads: Women's Psychology and Girls' Development. Cambridge, Mass.: Harvard University Press.

Bruner, J. (1990). Acts of Meaning. Cambridge, Mass.: Harvard University Press.

Bruner, J. (1994). The narrative construction of reality. In Psychoanalysis and Development: Representations and Narratives, ed. M. Ammaniti \& D.N. Stern. New York: New York University Press.

Charon, R. (2001). Narrative medicine: A model for empathy, reflection, profession, and trust. Journal of the American Medical Association 286: 1897-1902.

Cohler, B.J., Stott, F.M. \& Musick, J.S. (1995). Adversity, vulnerability, and resilience: Cultural and developmental perspectives. In Developmental Psychopathology, ed. D. Cicchetti \& D.J. Cohen. New York: John Wiley and Sons, Inc., pp. 753-800.

Derogatis, L.R. (1983). SCL-90 Administration and Scoring Manual. Towson, MD: Clinical Psychometric Research.

Diamond, J. (1995). Portrait of the biologist as a young man. In New York Review of Books. January 12.

Elliot, D.S. \& Ageton, S.S. (1980). Reconciling race and class differences in selfreported and official estimates of delinquency. American Sociology Review 45: 95-110.

Elliot, D.S. Ageton, S.S., Huinzega, D., Knowles, B.A. \& Canter, R.J. (1983). The Prevalence and Incidence of Delinquent Behavior: 1976-1980. Boulder, CO: Behavioral Research Institute.

Gjerde, P., Chang, R. \& Kremen, A. (1998). Life paths through adolescence: A study of developmental prototypes. Presented at Seventh Biennial Meeting of the Society for Research on Adolescence, San Diego, CA, February 27, 1998.

Harrington, C.C. \& Boardman, S.K. (1997). Paths to Success: Beating the Odds in American Society. Cambridge, MA: Harvard University Press.

Hazan, C. \& Shaver, P. (1987). Romantic love conceptualized as an attachment process. Journal of Personality and Social Psychology 52: 511-524.

Hauser, S.T., Jacobson, A., Noam, G. \& Powers, S. (1983). Ego development and self-image complexity in early adolescence: Longitudinal studies of diabetic and psychiatric patients. Archives of General Psychiatry 40: 325-332.

Hauser, S.T., Borman, E., Bowlds, M.K., Powers, S., Jacobson, A., Noam, G. \& Kroebbler, C. (1991). Understanding coping with adolescence: Ego development and coping styles. In Life Span Developmental Psychology: Perspectives 
on Stress and Coping, ed. A.L. Greene, E.M. Cummings \& K. Karraker. Hillsdale, NJ: Erlbaum Associates, pp. 177-194.

Hauser, S.T., Powers, S. \& Noam, G. (1991). Adolescents and Their Families: Paths of Ego Development. New York: Free Press.

Hy, L.X. \& Loevinger, L. (1986). Measuring ego development. Mahwah, NJ: Erlbaum Associates.

Kobak, R. \& Sceery, A. (1988). Attachment in late adolescence: Working models, affect regulation, and representations of self and others. Child Development 59: 135-146.

Lewis, M. (1987). Altering Fate: Why the Past Does Not Predict the Future. New York: Guilford.

Loevinger, J. (1976). Ego Development: Conceptions and Theories. San Francisco: Jossey-Bass.

Luthar, S.S., Cicchetti, D. \& Becher, B. (2000). The construct of resilience: A critical evaluation and guidelines for work. Child Development 71: 543-562.

Luthar, S.S. \& Cushing, G. (1999). Measurement issues in the empirical study of resilience: An overview. In Resiliency and Development: Positive Life Adaptations, ed. M. Glantz, Z. Sloboda \& L.C. Huffman. New York: Plenum, pp. 129 160.

Main, M. \& Goldwyn, R. (1998). Attachment scoring and classification systems (Version 6.1). Unpublished manual. Berkeley, University of California.

Masten, A., Best, K. \& Garmezy, N. (1990). Resilience and development: Contributions from the study of children who overcame adversity. Development and Psychopathology 2: 425-444.

Masten, A.S. (1996). In Fostering Resiliency in Kids: Overcoming Adversity. A congressional breakfast seminar. Consortium of Social Science Associations, Washington, D.C., pp. 19-24.

Mishler, E.G. (1995). Models of narrative analysis: A typology. Journal of Narrative and Life History 5(2): 87-123.

Reissman, K. (1993). Narrative Analysis. Newbury Park, CA: Sage.

Roosa, M. W. (2000). Some thoughts about resilience versus positive development, main effects versus interactions, and the value of resilience. Child Development 71: $567-569$.

Russell, D., Peplau \& Cutrona, C. (1980). The revised UCLA loneliness scale: Concurrent and discriminant validity evidence. Journal of Personality and Social Psychology 39: 472-480.

Rutter, M. (1987). Psychological resilience and protective mechanisms. American Journal of Orthopsychiatry 57: 316-331.

Safyer, A. \& Hauser, S.T. (1994). A microanalytic method for exploring adolescent emotion expressions. Journal of Adolescent Research 4: 487-502.

Sameroff, A.J., Seifer, R. \& Zax, M. (1982) Early development of children at risk for emotional disorder. Monographs of the Society for Research in Child Development 47(Series No. 199).

Schafer, R. (1992). Retelling a Life: Narration and Dialogue in Psychoanalysis. New York: Basic Books. 
Schultz, L.H. \& Selman, R.L. (1998). Ego development and interpersonal development in young adulthood. In Personality Development, ed. P.M. Wesbenberg, A. Blosi \& L. Cohn. Mahwah, NJ: Erlbaum, pp. 181-202.

Spence, D. (1982). Narrative Truth and Historical Truth: Meaning and Interpretation in Psychoanalysis. New York: Norton.

Vaillant, G. (1993). The Wisdom of the Ego. Cambridge (MA): Harvard University Press.

Verghese, A. (2001). The physician as storyteller. Annals of Internal Medicine 135: 1012-1017.

Wang, M.C. \& Gordon, E.W., ed. (1994). Educational Resilience in Inner-City America: Challenges and Prospects. Hillsdale, NJ: Lawrence Erlbaum Associates.

Werner, E.E. (1996). In Fostering Resiliency in Kids: Overcoming Adversity. A congressional breakfast seminar. Consortium of Social Science Associations, Washington, D.C., pp. 6-14.

Werner, E.E. \& Smith, R.S. (1992). Overcoming the Odds. Ithaca (NY): Cornell University Press.

Wilson, E. O. (1994). Naturalist. Washington, DC: Island Press/Shearwater Books.

\section{FIGURE CAPTIONS}

Figure 1. Resilience.

Figure 2. Resilience. Individual lives and trauma

Figure 3. Longitudinal analysis of resilient development. Follow-back design

Figure 4. Longitudinal design of young adult phase. Resilient functioning project 
